INTERNATIONAL JOURNAL OF RESEARCHES IN BIOSCIENCES, AGRICULTURE AND TECHNOLOGY (C) VISHWASHANTI MULTIPURPOSE SOCIETY (Global Peace Multipurpose Society) R. No. MH-659/13(N) www.ijrbat.in

\title{
SYNTHESIS AND CHARACTERIZATION OF GRAPHENE OXIDE/POLY (GLYCIDYL METHACRYLATE) NANOCOMPOSITES
}

\author{
Manish Kumar ${ }^{1}$, Navin Kumar Mogha ${ }^{1}$, Chetankumar B. Masram $^{2}$ and Dhanraj T. Masram ${ }^{1 *}$ \\ ${ }^{1}$ Department of Chemistry, University of Delhi, Delhi-110007, India \\ ${ }^{2}$ S.N.Mor College, Tumsar, RTM Nagpur University Nagpur, Maharashtra, India \\ dhanraj_masram27@rediffmail.com
}

\begin{abstract}
:
Graphene/graphene oxide (GO)-based polymer article is of great importance owing to its numerous functionalities. In this study, we successfully synthesized, a novel graphene oxide polymer nanocomposite (GO/PGMA). GO/PGMA had been synthesized by surface-initiated Atom transfer radicle polymerization technique and characterized by XRD, TEM and Raman spectroscopy. GO/PGMA dosage and temperature are also performed.
\end{abstract}

Keywords: Graphene oxide; Polymer; Nanocomposite; SI-ATRP

\section{INTRODUCTION:}

The single atom layer carbon material graphene oxide (GO) attracts a large number of attention due to its unique structural and different physical/chemical properties [1-3]. Due to the large specific surface area and high biocompatibility makes GO is a helping in supporting material for proteases conjugation via the surface hydroxyl or carbonyl groups of GO [4-6]. However, the potential of GO has not been fully exploited because of the relatively limited amount of functional groups on GO and possible unfavourable orientations of the surface conjugation proteases [7,8].Graphene oxide (GO) is the perfect candidate for the fabrication of artificial nacre with several functional groups on its surface [9]. The GO-based composite has shown different application for biological support such as energy storage,high power anodes [10],drug delivery, super capacitors [11] etc. Graphene oxide (GO) and graphene-based composites have been the interesting topic for many research groups around the world[12]. The strong interfacial interaction and the different layered structure of the graphene or GO-based composite are responsible for their unique mechanical performance. Two-dimensional graphene or GO sheets that served as the layered structure at nanoscale have ultrahigh tensile strength and modulus. During the construction of graphene or GO-based composite the interaction of the graphene or GO sheets has become the strategic point [13]. Graphene or GO-based composite are mainly constructed by three approaches, such as hydrogen bonding, ionic bonding and covalent bonding. Furthermore, different polymers have been attached to graphene sheets to give electrically conductive, fluorescent, transparent and flexible materials [14, 15]. Subsequent incorporation of polymer or polymeric material [16], helps in reducing graphene sheet agglomeration [17] giving rise to interesting and different graphene - polymer structures in the form of brushes [18], micelle, sponge etc. have also been realized.

\section{MATERIAL AND METHODS}

Graphite powder, glycidyl methacrylate (GMA), $\mathrm{N}, \mathrm{N}, \mathrm{N}^{\prime}, \mathrm{N}^{\prime}, \mathrm{N}^{\prime \prime}$-pentamethyldiethylenetriamine,

(PMDETA) were purchased from Alfa Aesar, India. a-Bromoisobutyryl bromide (BIB) was obtained from Spectrochem Pvt Ltd., India. All other materials used were of AR grade. De-ionized (DI) water has been used throughout present study.

\section{Characterization}

Morphological characterization was carried out using TECNAI 200 kV TEM (Fei, Electron Optics) equipped with digital imaging and $35 \mathrm{~mm}$ 
photography system. Raman spectrums were recorded by RenishawInvia Reflex Micro-Raman spectrometer in which the sample was excited by $514 \mathrm{~nm}$ wavelength $\mathrm{Ar}+$ laser. X-ray diffraction patterns were recorded using X-ray diffractometer (Model No. D8 DISCOVER) [19].

\section{Synthesis of GO and GO-Br}

GO was synthesized by improved hummer's method as reported earlier [32]. GO-Br was synthesised by sonication $200 \mathrm{mg}$ of GO was $10 \mathrm{ml} \mathrm{DMF}$ for $1 \mathrm{~h} .8$ $\mathrm{ml}$ TEA and $12 \mathrm{~mL}$ BIB were added to the resulted suspension at $0{ }^{\circ} \mathrm{C}$. The product was collected via filtration after $24 \mathrm{~h}$ and subsequently washed by chloroform $(3 \times 20 \mathrm{ml})$ with deionized water $(3 \times 20 \mathrm{ml})$ followed by dried under high vacuum for $18 \mathrm{~h}$.

Synthesis of Graphene oxide/Poly (glycidyl) methacrylate (GO/PGMA)nanocomposite

$100 \mathrm{mg}$ of GO-Br was sonicated in $5 \mathrm{ml}$ of DMF for 1 $\mathrm{h}$ followed by addition of $6 \mathrm{ml}$ GMA, 50mg $\mathrm{CuBr}$ and $75 \mu 1$ PMDETA. Reaction mixture was degassed using three freeze pump thaw cycles and heated for $24 \mathrm{~h}$ at $100{ }^{\circ} \mathrm{C}$. Resulting viscous solution was poured into $30 \mathrm{ml}$ ethanol to precipitate the product and remove unreacted monomer and catalyst followed by some more washing of the product by ethanol $(3 \times 50 \mathrm{ml})$, product was dried overnight in vacuum at $80^{\circ} \mathrm{C}$.

\section{RESULTS AND DISCUSSION}

\section{$X$-Ray diffraction and Raman Spectroscopic studies of GO/PGMA}

X-ray diffraction pattern and Raman spectra of GO and GO/PGMA are illustrated in Figure1. XRD patterns of GO in Figure 1(a) shows its characteristic peak at $2 \Theta=9.74$ with an interlayer spacing of $9.066 \AA$ represents plane $<001>$ and at $2 \Theta=42.64^{\circ}$ plane $<100>$ with interlayer spacing of 2.12 A. Broad merged peaks encircled in Figure 1(a) depicts XRD pattern of GO/PGMA representing the fused peaks of PGMA and RGO, formed due to the co-reduction of GO to RGO. Raman spectra of Graphene oxide characterised by the presence $\mathrm{D}$ and $G$ peaks. The characteristic $D$ peak in graphene is due to breathing mode $\mathrm{j}$-point phonons of $\mathrm{A}_{1} \mathrm{~g}$ symmetry associated with $\mathrm{sp}^{3}$ bonded carbon atoms in disordered graphene whereas, peak $\mathrm{G}$ is assigned due to first order scattering of $E_{2} g$ phonons in $\mathrm{sp}^{2}$ bonded carbon atoms. Raman spectra of GO and GO/PGMA are shown in Fig. 1 (b). Raman spectra of GO shows $G$ peak at $1600 \mathrm{~cm}^{-1}$ and $D$ peak at 1350 $\mathrm{cm}^{-1}$. Same bands for GO/PGMA are observed to be shifted due to polymer functionalization on GO surface. Intensity ratio of $\mathrm{D}$ and $\mathrm{G}$ band $\left(\mathrm{I}_{\mathrm{D}} / \mathrm{I}_{\mathrm{G}}\right.$ ratio) indicates disorderness in the material are found to be $0.86,1.34$ for GO, and GO/PGMA respectively. Increase in the $I_{D} / I_{G}$ ratio from $G O$ to GO/PGMA is due to increased $\mathrm{sp}^{3}$ character attributable to growth of polymer brushes over GO surface.

\section{Morphological Characterization}

TEM has been used for morphological characterization of GO and GO/PGMA as depicted in figure 2. Fig 2(a), TEM micrograph shows characteristic sheet like morphology with wrinkles of GO. Whereas, figure 2(b) shows the GO/PGMA micrograph where small spherical structures of Poly(glycidyl) methacrylate over surface of GO can be observed. These polymers are giving a porous morphology to GO/PGMA, which is contributing to its adsorption properties.

\section{CONCLUSION :}

GO/PGMA had been synthesized by surface initiated Atom transfer radicle polymerization technique. GO/PGMA was characterized by X-ray diffraction, Raman spectroscopy and TEM for morphological characterization.PGMA was used as an active adhesive which is produce a layered sheet of graphene oxide/polymer composite. Now compared with other composites the GO/PGMA composites exhibited enhanced mechanical and electrical properties, such as toughness, higher tensile stress, and dielectric constant. Furthermore, the GO/PGMA composites shown better mechanical properties than other GO-based films. Thus, the 
GO/PGMA composites show extensive potential applications such as electronic and engineering materials.

\section{ACKNOWLEDGEMENT}

Authors are obliged for the financial supported from DU-DST Purse Grant Phase II (2016) Ref. No. CD/2016/1761 by University of Delhi, Delhi, India and SERB-DST (SB/EMEQ-081/2014) Delhi,India. Authors are also grateful to Sophisticated Analytical Instrument Facility (SAIF) - AIIMS, New Delhi, under the SAIF Program of DST for providing TEM facility.

\section{REFERANCE :}

Tu YS, Lv M, Xiu P, Huynh T, Zhang M, Castelli M, et al. Destructive extraction of phospholipids from Escherichia coli membranes by graphene nanosheets. Nat Nanotechnol. 2013; 8 (8): 594601. 25.

Chua CK, Pumera M. Chemical reduction of graphene oxide: a synthetic chemistry viewpoint. ChemSoc Rev. 2014; 43(1):291- 312.

Gao W, Lee HK, Hobley J, Liu TX, Phang IY, Ling $\mathrm{XY}$. Graphene liquid marbles as photothermal miniature reactors for reaction kinetics modulation. AngewChem-Int Edit. 2015; 54(13):3993-6.

Jiang B, Yang KG, Zhao Q, Wu Q, Liang Z, Zhang LH, et al. Hydrophilic immobilized trypsin reactor with magnetic graphene oxide as support for high efficient proteome digestion. J Chromatogr A. 2012; 1254:8-13.

Jiao J, Miao AZ, Zhang XY, Cai Y, Lu Y, Zhang Y, et al. Realization of on-tissue protein identification by highly efficient in situ digestion with graphene-immobilized trypsin for MALDI imaging analysis. Analyst. 2013; 138 (6):16458.

Bai HH, Pan YT, Ren XJ, Hao FR, Deng SS, Fan C, et al. An ultrafast and highly efficient multiple proteases digestion strategy using graphene- oxide-based immobilized protease reagents. SciChinaChem. 2014; 57 (5):695-702.

Jiang B, Yang KG, Zhang LH, Liang Z, Peng XJ, Zhang YK. Dendrimer-grafted graphene oxide nanosheets as novel support for trypsin immobilization to achieve fast on-plate digestion of proteins. Talanta. 2014;122: 278-84.

Shi CY, Deng CH, Li Y, Zhang XM, Yang PY. Hydrophilic polydopamine-coated magnetic graphene nanocomposites for highly efficient tryptic immobilization. Proteomics. 2014; 14(12):1457- 63.

S. Stankovich, D.A. Dikin, G.H.B. Dommett, K.M. Kohlhaas, E.J. Zimney, E.A. Stach, R.D. Piner, S.T. Nguyen, R.S. Ruoff, Graphene-based composite materials, Nature. 442 (2006) 282 286. doi:10.1038/nature04969.

N.K. Mogha, V. Sahu, M. Sharma, R.K. Sharma, D.T. Masram, Biocompatible $\mathrm{ZrO} 2-$ reduced graphene oxide immobilized AChE biosensor for chlorpyrifos detection, Mater. Des. 111 (2016) 312-320. doi:10.1016/j.matdes.2016.09.019.

N.K. Mogha, V. Sahu, M. Sharma, R.K. Sharma, D.T. Masram, Sensitive and Reliable Ascorbic Acid Sensing by Lanthanum Oxide/Reduced Graphene Oxide Nanocomposite, Appl. Biochem. Biotechnol. 174 (2014) 1010-1020. doi: $10.1007 / \mathrm{s} 12010-014-0986-z$.

D. Chen, L. Tang, J. Li, Graphene-based materials in electrochemistry, Chem. Soc. Rev. 39 (2010) 3157-3180. doi:10.1039/b923596e.

M. He, J. Jung, F. Qiu, Z. Lin, Graphene-based transparent flexible electrodes for polymer solar cells, J. Mater. Chem. (2012) 24254-24264. doi:10.1039/c2jm33784c.

K. Batrakov, P. Kuzhir, S. Maksimenko, A. Paddubskaya, S. Voronovich, P. Lambin, T. Kaplas, Y. Svirko, multilayers for efficient electromagnetic, (2014) $1-5$. doi:10.1038/srep07191. 
P.G. Sponges, Highly Electrically Conductive Nanocomposites Based on Polymer-Infused Graphene Sponges, (2014) 1-6. doi:10.1038/srep04652.

M. Fang, K. Wang, H. Lu, S. Nutt, Covalent polymer functionalization of graphene nanosheets and mechanical properties of composites, i (2009) 7098-7105. doi:10.1039/b908220d.
C.I. Wang, A.P. Periasamy, H.T. Chang, Photoluminescent C-dots@RGO probe for sensitive and selective detection of acetylcholine, Anal. Chem. 85 (2013) 32633270. doi:10.1021/ac303613d.

S. Hu, Q. Huang, Y. Lin, C. Wei, H. Zhang, W. Zhang, Z. Guo, X. Bao, J. Shi, A. Hao, Reduced graphene oxide-carbon dots composite as an enhanced material for electrochemical determination of dopamine, Electrochim. Acta. 130 (2014) 805-809. doi:10.1016/j.electacta.2014.02.150.

I. Choi, D.D. Kulkarni, W. Xu, C. Tsitsilianis, V. V Tsukruk, Star Polymer Unimicelles on Graphene Oxide Flakes, (2013).
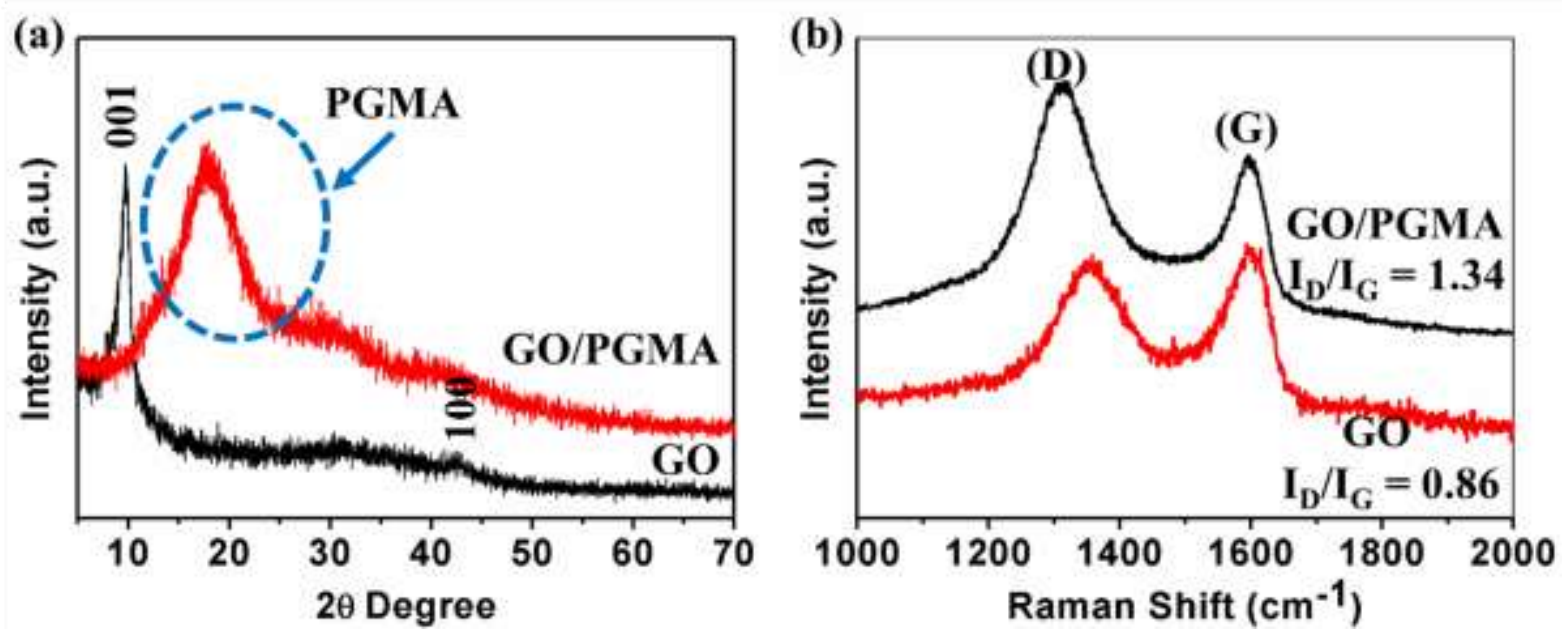

Figure 1, (a) XRD and (b) Raman Spectra of GO and GO/PGMA

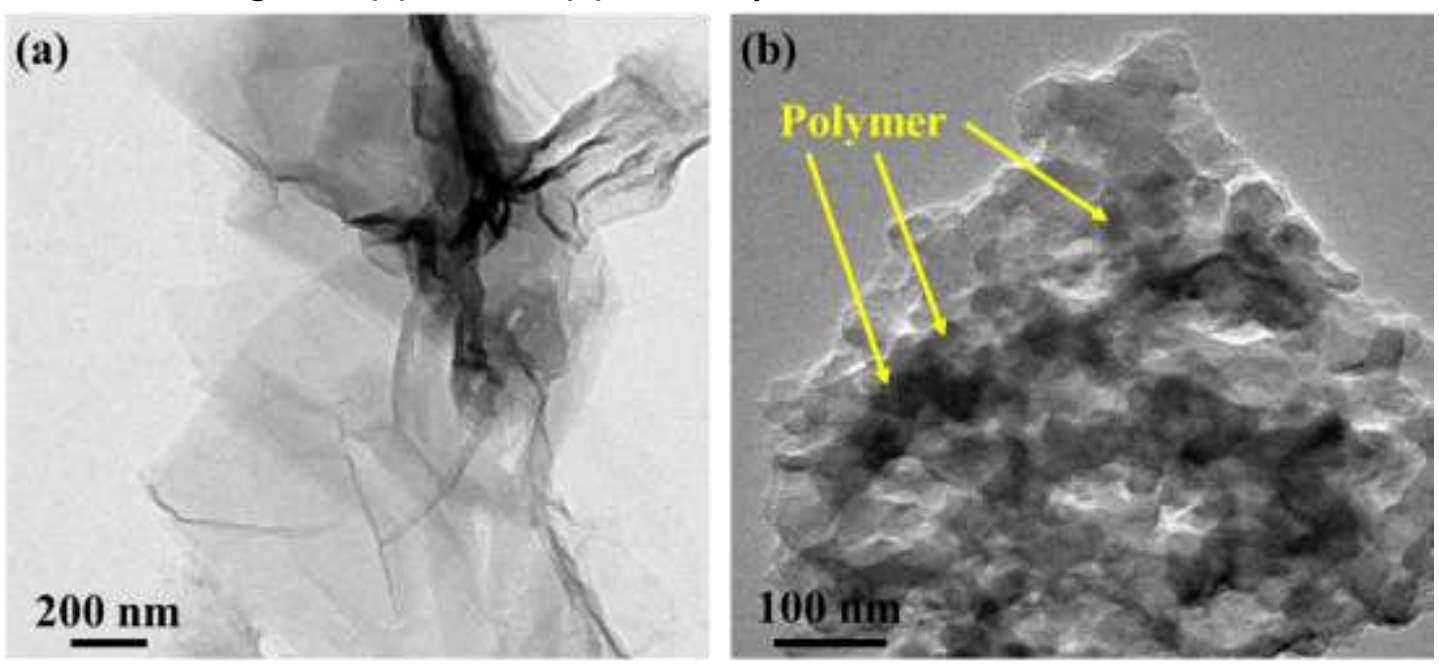

Figure 2, (a) TEM micrograph of GO and (b) GO/PGMA 